\title{
FORMACÃO CONTINUADA DE PROFESSORES DOS ANOS INICIAIS DA EDUCAÇ̃̃O BÁSICA: IMPACTO DO PROGRAMA FORMATIVO DE UM MUSEU DE CIÊNCIA A PARTIR DO VIÉS CRÍTICO-REFLEXIVO ${ }^{1}$
}

\author{
Grazielle Rodrigues Pereira* \\ Livia Mascarenhas de Paula** \\ Lilian Mascarenhas de Paula*** \\ Robson Coutinho-Silva***
}

RESUMO: No presente trabalho, objetivamos avaliar um curso de formação continuada para professores dos anos iniciais do Ensino Fundamental oferecido por um museu de ciência, localizado em uma região de grande vulnerabilidade social da Baixada Fluminense no Estado do Rio de Janeiro. O curso se baseou no modelo críticoreflexivo, bem como a avaliação transcorreu após um semestre do término das atividades, por meio de entrevista semiestruturada e análise de fotografias. Com os resultados, verificamos mudanças significativas nas práticas dos docentes como a inserção de novas metodologias, interdisciplinaridade, planejamento e organização da disciplina de Ciências. Dessa forma, os docentes compreenderam a importância das Ciências para os anos iniciais, assim como reconheceram as diferentes possibilidades e potencialidades da disciplina para uma educação mais holística da criança.

Palavras-Chave: Ensino de Ciências. anos iniciais do Ensino Fundamental. Formação continuada de professores.

\section{FORMACIÓN CONTINUADA DE PROFESORES DE LOS AÑOS INICIALES DE LA EDUCACIÓN BÁSICA: IMPACTO DEL PROGRAMA FORMATIVO DE UN MUSEO DE LAS CIENCIAS A PARTIR DE LA TENDENCIA CRÍTICA-REFLEXIVA}

RESUMEN: En este trabajo, el objetivo fue evaluar un taller de formación continuada para profesores de los años iniciales de la Primaria ofrecido por un museo de las ciencias, ubicado en una región de grande vulnerabilidad social de la Baixada Fluminense del Estado del Rio de Janeiro. El taller se basó en el modelo crítico-reflexivo, bien como la evaluación transcurrió después de un semestre del término de las actividades, por medio de entrevista semiestructurada y análisis de fotografías. Con los resultados, verificamos cambios significativos en las prácticas de los docentes, como la inserción de nuevas metodologías, interdisciplinaridad, planificación y organización de la disciplina de las Ciencias. De esta manera, los docentes comprendieron la importancia de las Ciencias para los años iniciales, así como reconocieron las diferentes posibilidades y potencialidades de la disciplina para una educación más holística del niño.

Palabras clave: Enseñanza de las Ciencias. Años iniciales de la Primaria. Formación continuada de profesores.
*Doutora em Ciência Biológicas . Biofísica pela Universidade Rio de Janeiro, RJ - Brasil. Docente e pesquisadora do Programa de Pós-graduação em Educação e Divulgação Científica do IFRJ, do Programa de Mestrado em Ensino de Ciências do IFRJ e do Programa de Mestrado Profissional em Educação, Gestão e Difusão em Ciências do IBqM/UFRJ. Diretorageral do Campus Mesquita/Espaço Ciência InterAtiva do IFRJ. E-mail:

< grazielle.pereira@ifrj.edu.br >

* * Doutoranda em Ensino em Biociências e Saúde pelo Instituto Oswaldo Cruz (IOC/FIOCRUZ), Rio de Janeiro, RJ - Brasil.

Produtora cultural da Universidade Federal do Rio de Janeiro e colaboradora do Espaço Ciência Viva e do Espaço Ciência InterAtiva do IFRJ. E-mail:

< liviampcunha@gmail.com >

* * * Licencianda em pedagogia, professora dos anos iniciais na Prefeitura Municipal de Nova Iguaçu, Rio de Janeiro, RJ - Brasil. Colaboradora do Espaco Ciência interativa do IFRJ. E-mail:

< lilian.mascarenhas7@gmail.com>

***Doutor em Ciências Biológicas . Biofísica pela Universidade Federal do Rio de Janeiro (UFRJ), Rio de Janeiro, RJ - Brasil. Professor Titular e Coordenador do Programa de Imunobiologia do Instituto de Biofísica Carlos Programa de Pós-Graduação em Ensino de Biociências e Saúde FIOCRUZ; Presidente do Museu de Ciências Espaço Ciência Viva. Email: Federal do Rio de Janeiro (UFRJ), Chagas Filho - UFRJ, Professor do 
CONTINUING TEACHERS' EDUCATION IN ELEMENTARY SCHOOL'S EARLY YEARS: THE IMPACT OF A SCIENCE MUSEUM'S CONTINUING EDUCATION PROGRAM FROM CRITICAL-REFLECTIVE BIAS

ABSTRACT: In this study, we aim to evaluate a science museum's continuing education course for teachers that work with elementary school's early years, from a socially vulnerable region in Baixada Fluminense at Rio de Janeiro state. This course was based on the critical-reflective approach and the evaluation was done one semester after the activity's completion, through semi-structured interviews and photo analysis. With the results, we found significant changes in teachers' practices and new methodologies' inclusion, interdisciplinarity, planning and organization of the science course. Thus, the teachers understood the importance of science to the early years, and recognized the different possibilities and potentials of the discipline for the child's holistic education.

Keywords: Science education. Early years of elementary school. Continuing teacher education. 


\section{INTRODUÇÃO}

Observamos, no cenário brasileiro, a precarização do ensino de Ciências nos anos iniciais da educação básica (DELIZOICOV; ANGOT'TI, 2000; CARVALHO; GIL PÉREZ, 2011). Os professores, por sua vez, encontram muitos obstáculos para a promoção do ensino de Ciências, como a ausência de infraestrutura e de material adequado para a realização das aulas (RAMOS; ROSA, 2008); despreparo para o ensino da disciplina em função da precariedade na formação inicial e continuada (LONGHINI, 2008; AUGUSTO, 2010; PEREIRA, 2014), além da falta de apoio da gestão escolar ao priorizar a alfabetização e a Matemática nos anos inicias da escolarização (PEREIRA et al., 2013). Mudar tal realidade requer do professor a identificação e o aprofundamento das relações entre as diferentes disciplinas que compõem a grade curricular dos anos iniciais da educação básica, bem como suas áreas correlatas (Ibid.).

Diversos trabalhos apontam para a necessidade de ações em relação à educação básica a fim de minimizar e demover os problemas presentes no ensino de Ciências, especialmente no que tange à formação dos professores (NÓVOA, 1995; JACOBUCCI, 2006; CARVALHO; GIL PÉREZ, 2011). Dessa forma, é de grande urgência a implementação de programas formativos em Ciências para tais docentes, a partir de estratégias metodológicas e mecanismos que promovam a autonomia e a mudança na prática do professor. Em face das diferentes questões que permeiam a formação continuada de professores, cabe ressaltar que as práticas de formação permanente não se restringem aos espaços de educação formal (escolas, universidades), pois há atualmente muitas instituições de educação não formal, como os Centros e Museus de Ciência, que promovem atividades de formação de professores.

Ao considerar o processo de formação de professores em espaços formais e não formais da educação, iremos notar que os princípios metodológicos e pedagógicos que regem os processos de formação em instituições formais também orientam os programas formativos na educação não formal. Jacobucci (2006) investigou 14 programas de formação continuada de professores oferecidos por 11 centros e museus de ciência brasileiros e estabeleceu três categorias para os modelos de formação de professores: clássico, prático-reflexivo e emancipatóriopolítico. Após a análise dos resultados, a autora verificou que dos 14 programas formativos, seis estão estruturados com características do modelo clássico de formação de professores. Ao descrever o modelo clássico, a autora esclarece que:

\footnotetext{
O planejamento e a estruturação do programa de formação no modelo clássico ocorrem sem participação dos professores-alunos e a equipe propositora elabora e aplica as atividades. Estas propostas são oferecidas na forma de palestras, oficinas, seminários e, principalmente, cursos de capacitação ou treinamento. [...] utiliza-se frequentemente uma metodologia de ensino tradicional, [...], sem haver interação e troca de experiências entre as partes. Há ausência de discussão acerca da prática pedagógica e dos problemas escolares e sociais relacionados ao exercício da profissão (JACOBUCCI; JACOBUCCI; MEGID NETO, 2011, p. 6).
} 
Em outro estudo, Paula et al (2014) realizaram um levantamento em 79 museus e centros de Ciência distribuídos em 24 países. Os pesquisadores verificaram que, dentre os espaços investigados, 19 ofereciam programas de formação continuada de professores. Quanto às características das ações de formação, prevaleceram os programas na modalidade oficinas e workshops, com atividades de curta duração, visando à atualização e qualificação profissional em Ciências (Física, Química, Ciências da Terra, Astronomia, Biologia) e/ou Matemática (PAULA et al, 2014). Diante do exposto, podemos observar, em diferentes contextos, programas formativos com o objetivo de apenas instrumentalizar o professor sobre determinados conteúdos científicos. Nessa corrente, Augusto (2010) afirma que as diferentes ações de formação continuada têm se ancorado em cursos pontuais e estanques, "que geralmente não respondem às necessidades dos professores. Ademais, não há coerência entre o ensino praticado na formação continuada e o ensino preconizado pelos mesmos cursos" (AUGUSTO, 2010, p. 142).

Jacobucci (2006) destaca que há a ausência de avaliação nos programas de formação ofertados aos professores pelos centros e museus de ciência. Por isso, no presente trabalho, objetivamos apresentar os resultados da avaliação do programa formativo do Espaço Ciência InterAtiva, museu de ciência do Instituto Federal de Educação, Ciência e Tecnologia, baseado no modelo crítico-reflexivo (ALARCÃO, 1996; PIMENTA, 2008; ZEICHNER, 2008; CONTRERAS, 2012). Dessa maneira, buscamos responder à seguinte questão: programas formativos desenvolvidos por museus de ciência podem promover impactos que gerem no professor dos anos iniciais da educação básica transformações na educação científica? Consideramos as mudanças no contexto escolar e a valorização do ensino de Ciências por parte do docente como aspectos relevantes no processo de avaliação do programa formativo.

Importa destacar que o Programa de Formação Continuada de Professores do Espaço Ciência InterAtiva, do Instituto Federal de Educação, Ciência e Tecnologia do Rio de Janeiro, é um recorte do projeto "Ciências, Linguagens e Atividades Interativas na Educação Básica”, do Programa Observatório da Educação. ${ }^{2}$

\section{A FORMAC̣ÃO CONTINUADA DE PROFESSORES E O MODELO CRÍTICO-REFLEXIVO}

Vários modelos têm sido propostos para a formação de professores ao longo das últimas décadas; todavia, há um número significativo de programas que trazem poucas contribuições para a prática. Dessa forma, "propor cursos de formação continuada, para profissionais que estão em sala de aula, já há algum tempo, requer que olhemos para as reais condições daqueles que vão oferecer e daqueles que vão frequentar" o curso (VIANA; CARVALHO, 2000, p. 32).

Diante das diferentes tendências e abordagens dos programas de formação continuada de professores, percebemos a predominância de práticas que nem sempre procuram atender às necessidades pedagógicas dos professores, nas quais o docente cursista desempenha o papel de ouvinte, e se desconhece que ele tem muito a contribuir e não somente aprender.

Um dos modelos que têm orientado as práticas atuais de formação inicial e continuada de professores é o modelo do professor "prático reflexivo", 
baseado nos estudos de Donald Schön, na década de 1980, direcionado à educação profissional. Segundo o autor, é a partir da reflexão sobre a própria prática que as transformações podem acontecer (SCHÖN, 1987). Todavia, Alarcão (1996), ao transpor essas teorias para o professor, tece as seguintes considerações:

[...] o conceito de professor reflexivo não se esgota no imediato da sua ação docente. Ser professor implica saber quem sou, as razões pelas quais faço o que faço, consciencializar-se do lugar que ocupo na sociedade. Numa perspectiva de promoção do estatuto da profissão docente, os professores têm de ser agentes activos do seu próprio desenvolvimento e do funcionamento das escolas como organização ao serviço do grande projecto social que é a formação dos educandos (p. 177).

Na perspectiva de ampliar as ideias de Schön, Pimenta (2008) destaca que a prática reflexiva deve ultrapassar as práticas individuais e, assim, requer uma mudança no coletivo, de modo a alcançar um processo de transformação institucional e social. Para Zeichner (1995), os programas de formação para professores a partir de treinamentos são um pacote de conteúdos e não condizem com a prática reflexiva do docente. São capacitações que não promovem o engajamento mais crítico por parte do professor, tendo como proposta treinar o indivíduo, mediante a técnica. Com isso, diante das problemáticas vivenciadas pelo docente, faz-se necessária a tomada de decisões, quando o professor precisa sair da inércia e tomar posições concretas, com o objetivo de minimizar, ou, mesmo, dirimir os entraves presentes no sistema educacional (Ibid.).

Pimenta (2008) chama a atenção para a realidade brasileira ao expor que há países como o Brasil, onde há uma "tendência em proceder a uma tecnicização da reflexão, a partir de sua operacionalização em inúmeras competências a serem desenvolvidas no processo formativo" (PIMENTA, 2008, p. 46). De modo que não há uma análise crítica da prática docente, e os docentes, responsáveis pelos processos de formação, são transformados em tutores e monitores da aprendizagem.

Em oposição aos enganos gerados pelo termo "reflexão", Zeichner legitimou o movimento prático reflexivo, a partir da defesa do papel ativo do professor, sobretudo na formulação dos objetivos e meios de trabalho. O autor admite que o docente "também tem teorias que podem contribuir para a construção de conhecimentos sobre o ensino” (LIBÂNEO, 2008, p. 65). Para tanto, a partir da premissa do professor prático reflexivo como um indivíduo crítico, Nóvoa (1995) faz as seguintes colocações:

[...] a formação não se constrói por acumulação (de cursos, de conhecimentos ou de técnicas), mas sim através de um trabalho de reflexividade crítica sobre as práticas e de (re) construção permanente de uma identidade pessoal. Por isso é tão importante investir na pessoa e dar estatuto ao saber da experiência. (p. 25)

No que tange à necessidade de ressignificação do termo reflexivo e, considerando a formação de professores reflexivos, é consenso entre os autores (ALARCÃO, 1996; PIMENTA, 2008; ZEICHNER, 2008; CONTRERAS, 2012) a necessidade da formação docente aliada a uma reflexão crítica que promova 
debates acerca das questões sociais e políticas, ou seja, a formação de docentes críticos reflexivos.

Portanto, a formação do professor não pode restringir-se à atualização científica, uma vez que o êxito de um programa de formação continuada de professores é determinado pelas necessidades individuais de cada participante envolvido, respeitando sua cultura, anseios e realidade social. Dessa forma, deve contemplar situações retiradas diretamente do contexto de cada professor; a fim de assegurar ao sujeito a apropriação contínua do conhecimento, deve promover mudanças no contexto escolar, fomentando o crescimento individual e coletivo de seus alunos para além das atividades em si (NÓVOA, 1995).

Para tanto, o programa formativo baseado no modelo crítico reflexivo denota a possibilidade de promoção de um espaço de atividades que facilitem discussões científicas atualizadas, fomentando debates que contribuam para múltiplas reflexões sobre o ambiente escolar e a educação no cenário brasileiro.

\section{METODOLOGIA}

Neste trabalho, apresentaremos os dados das duas primeiras turmas do programa formativo do Espaço Ciência InterAtiva. Iniciaremos, apresentando a metodologia aplicada durante o processo de desenvolvimento e realização das atividades do programa. Em seguida, demonstraremos os procedimentos para a avaliação do programa pelos professores concluintes.

\section{Desenvolvimento e realização do programa de formação}

O programa formativo configurou-se em um curso, denominado Curso de Formação Continuada de Professores em Ciências Naturais (CFCP), com carga horária de 100 horas, realizado no museu de ciência, Espaço Ciência InterAtiva (ECI) do Instituto Federal de Educação, Ciência e Tecnologia do Rio de Janeiro (IFRJ). O ECI está localizado no município de Mesquita, na Baixada Fluminense, região Metropolitana do Rio de Janeiro.

O curso foi estruturado a partir da integração entre os pesquisadores e professores das instituições envolvidas no projeto do Programa Observatório da Educação: o Espaço Ciência Viva (ECV), o Instituto de Biofísica Carlos Chagas Filho (IBCCF) da Universidade Federal do Rio de Janeiro e o Espaço Ciência InterAtiva. Também contou com a colaboração dos profissionais das instituições parceiras: o IFRJ/Campus Nilópolis e o IFRJ/Campus Duque de Caxias, a Fundação CECIERJ, a Universidade Federal Fluminense, além dos Centros e Museus de Ciência do Rio de Janeiro, como o Museu de Astronomia e Ciências Afins, a Casa da Ciência, o Museu Ciência e Vida, o Museu da Vida e o Espaço Memorial Carlos Chagas Filho do IBCCF.

Durante o período de desenvolvimento do curso, buscamos ouvir o potencial participante do CFCP (os professores dos anos iniciais do Ensino Fundamental), visando adequar o curso às necessidades desses docentes. Com isso, aplicamos questionários a 101 professores de escolas localizadas na Baixada Fluminense, bem como realizamos visitas a duas escolas do município de Mesquita, 
seis meses antes da abertura do processo de inscrição para o CFCP. Tal estratégia contribuiu para verificarmos as realidades dessas escolas em conversas informais com as direções, coordenações pedagógicas e alguns docentes dos anos iniciais. A escolha dessas escolas se deu em virtude da facilidade de inserção no campo por prévia autorização da gestão responsável e, por ofertarem, na ocasião, turmas dos anos iniciais do Ensino Fundamental.

Com o levantamento prévio, traçamos o perfil de cada professor participante, de modo que foram obtidas informações a respeito das disciplinas científicas cursadas durante sua formação inicial, sugestões de temas a ser tratados ao longo do curso, metodologias, carga horária, dias e horários para a realização do curso.

Por conseguinte, a definição dos temas a ser abordados durante os encontros foi norteada pelas respostas aos questionários, assim como pelos debates ocorridos previamente com a equipe de pesquisadores das diferentes instituições parceiras, em consonância com os Parâmetros Curriculares Nacionais de Ciências Naturais de $1^{\mathrm{a}}$ a $4^{\mathrm{a}}$ série - PCN (BRASIL, 1997). Para tanto, o curso foi dividido em sete módulos: 1- $\mathrm{O}$ ensino de Ciências nos anos iniciais da educação básica; 2- Educação Ambiental; 3- Corpo Humano, Saúde e Sexualidade; 4Ciência e Arte; 5- Neuroeducação; 6- Astronomia; 7- Fontes e Transformações de Energia. Os temas dos módulos "Neuroeducação" e "Ciência e Arte" não foram sugeridos pelos professores dos anos inicias. No entanto, a equipe responsável pelo curso julgou importante a presença desses temas, com o intuito de subsidiar e orientar os professores no processo de ensino e aprendizagem dos alunos. Com a introdução do módulo "Neuroeducação" foram debatidos temas como - "O Desenvolvimento do Sistema Nervoso da Criança", "Linguagem e Inteligência", "Distúrbios de Aprendizagem" e "Memória e Aprendizado". O módulo "Ciência e Arte" objetivou apresentar ferramentas para que os professores pudessem utilizar a arte para ensinar as Ciências da Natureza, principalmente a partir de elementos como filmes, desenhos animados, teatro, música, literatura e artes plásticas. Sob a perspectiva do programa formativo baseado na formação crítico-reflexiva, buscamos a articulação entre os diferentes campos científicos que compõem a disciplina de Ciências nos anos iniciais: Física, Química, Biologia, Astronomia, Geociências e as subáreas como a Sexualidade e o Meio Ambiente e também, com as disciplinas de Língua Portuguesa e Matemática.

Nas duas primeiras edições do curso, os temas foram mediados por professores e pesquisadores do ECI, ECV, IBCCF/UFRJ, UFF, IFRJ (Campi Nilópolis e Duque de Caxias) e da Fundação CECIERJ. As atividades foram divididas em encontros presenciais no ECI e visitas técnicas aos seguintes espaços de educação não formal: Parque Municipal de Nova Iguaçu, Espaço Ciência Viva, Casa da Ciência, Museu da Vida, Museu Ciência e Vida, Museu de Astronomia e Ciências Afins, Memorial Carlos Chagas Filho da Universidade Federal do Rio de Janeiro e nas exposições do Espaço Ciência InterAtiva. Realizamos, ainda, uma visita ao Laboratório de Imunofisiologia do Instituto de Biofísica Carlos Chagas Filho da UFRJ.

Os encontros no ECI abarcaram a realização de atividades práticas, palestras, debates de vídeos, leitura e discussão de artigos científicos. Cabe ressaltar que todo o material (kits experimentais, material didático) construído pelo grupo durante as aulas, além dos livros e DVDs explorados ao longo dos encontros, foi 
distribuído a cada participante para ser utilizado em suas escolas. Os materiais didáticos e kits experimentais foram utilizados para tratar dos assuntos relativos aos temas da Física, Química, Neuroeducação, Educação Ambiental, Astronomia, Sexualidade, Corpo Humano e Ciência e Arte.

Norteados pelo modelo crítico-reflexivo (ALARCÃO, 1996; PIMENTA, 2008; ZEICHNER, 2008; CONTRERAS, 2012), iniciávamos as dinâmicas de cada encontro a partir do relato dos professores participantes sobre suas percepções acerca do ensino de Ciências nos anos iniciais da educação básica, seu papel na sociedade, assim como questões do cotidiano escolar, do trabalho docente e suas ações em sala de aula com os estudantes. Nesse contexto, Contreras (2012) problematiza a necessidade de o docente compreender que a prática pedagógica precisa refletir o perfil de um profissional autônomo, crítico e reflexivo, que leva em conta o ambiente escolar, os fatores sociais, culturais e políticos. Dessa maneira, as discussões acerca da prática pedagógica e dos problemas escolares e sociais eram recorrentes ao longo do CFCP, para pensar, em conjunto, possibilidades de transformações na sala de aula, no espaço escolar e na educação científica.

\section{Avaliação após um semestre de término do curso}

Este trabalho integrou parte da pesquisa de tese de doutorado da primeira autora. Assim o curso foi avaliado por meio de outros instrumentos: grupos focais, questionários, registros fotográficos e análise de relatos verbais. As avaliações ocorreram durante todos os encontros, além da avaliação final no último dia de aula.

Apresentaremos, nesta pesquisa, os resultados do impacto do curso sobre os docentes após um semestre de término das atividades. Para tal, utilizamos para a coleta de dados o registro fotográfico e a técnica da entrevista semiestruturada de forma individual, com o professor concluinte. A entrevista se baseou no seguinte roteiro: - Você já havia participado de cursos nas áreas de ciências?; - Faça um relato a respeito das suas aulas de ciências antes, durante e após a sua participação no curso de formação de professores do ECI; - Foi possível incorporar alguma prática pedagógica e/ou atividades sugeridas pelo curso em suas aulas?; - O que foi efetivamente incorporado?; - Você encontrou dificuldades para implantar tais mudanças?; - Como você hoje avalia o ensino de ciências nos anos iniciais do Ensino Fundamental?; -Você consegue articular a ciência com outras áreas do conhecimento?; - Hoje você encontra dificuldades para tratar de temas em ciências em sala de aula?; - Há algum tema de ciências com o qual você se sente inseguro, e que gostaria que o curso tivesse explorado?; - Você tem utilizado o material distribuído ao longo do curso em suas aulas? Faça alguns relatos; - Como você hoje prepara as suas aulas de ciências? Quais recursos você utiliza?; - O planejamento curricular sofreu mudanças após sua participação no curso?

No tocante à preparação de roteiros antes da entrevista semiestruturada, Lüdke e André (1986) esclarecem que: “[...] essa metodologia permite que o entrevistador faça as necessárias adaptações [...] não há imposição de uma ordem rígida de questões, o entrevistado discorre sobre o tema com base nas informações que ele detém" (p. 34). Por conseguinte, as questões do roteiro foram necessariamente abordadas ao longo das entrevistas, sendo que outras perguntas foram elaboradas 
à medida que as julgávamos importantes para a aquisição de novas informações.

A escolha do intervalo de tempo de seis meses se deu em virtude da necessidade de avaliarmos o impacto do programa formativo sem a intervenção direta da equipe do CFCP, como também respeitamos a disponibilidade dos professores para participar da pesquisa. Com isso, algumas entrevistas aconteceram após oito meses de término do curso. Nessa etapa da pesquisa, a coleta de dados se deu com 15 professores, todos regentes de turma da rede pública de ensino, sendo 12 da primeira turma e três docentes da segunda turma. Parte dos professores das duas primeiras turmas do CFCP não se disponibilizou para participar da entrevista, assim como três professores, após a conclusão do curso, passaram a integrar o projeto "Ciências, Linguagens e Atividades Interativas na Educação Básica”, do Programa Observatório da Educação e, por conseguinte, foram excluídos dessa etapa da pesquisa. As dinâmicas das entrevistas se iniciaram a partir da apresentação oral da síntese do projeto aos sujeitos da pesquisa, etapa na qual todas as entrevistas foram filmadas. $\mathrm{O}$ uso das filmagens contribuiu para o trabalho de análise dos dados, a partir de gestos, expressões orais, entonações ao longo dos depoimentos, entre outros.

O registro fotográfico também foi importante no processo de coleta de dados, uma vez que os participantes da entrevista nos enviaram fotografias das atividades realizadas após um semestre de término do curso. Segundo NeivaFilho e Koller (2002), a fotografia pode assumir a função de registro, "na qual a fotografia tem o papel de documentar determinada ocorrência" (p. 238). Dessa maneira, os autores explicam que "fotografa-se um certo evento durante o seu acontecimento e, posteriormente, esta imagem é tomada como um dado de pesquisa na análise específica do motivo fotográfico, isto é, da ação, pessoa ou objeto fotografados" (Ibid). Assim, de posse das fotografias, realizamos a análise dos registros fotográficos das ações dos professores no ambiente escolar. Cabe registrar que obtivemos a autorizarão prévia dos participantes da pesquisa para o uso das imagens e filmagens nos dois momentos da pesquisa.

Para a análise e interpretação dos dados, empregamos a técnica da análise de conteúdo (BARDIN, 2013). Todo o material produzido ao longo da coleta de dados foi transformado em unidades de registro e, em seguida foram inseridas nas categorias temáticas previamente estabelecidas. Bardin (2013) esclarece que, na análise de conteúdo, as categorias temáticas são classes que reúnem unidades de registro com características comuns. Na sequência, Moraes (1999) detalha que "A categorização é um procedimento de agrupar dados considerando a parte comum existente entre eles. Classifica-se por semelhança ou analogia, segundo critérios previamente estabelecidos ou definidos no processo" (p. 6).

Após estabelecermos as unidades de registro, definimos duas categorias temáticas - "aumento da habilidade profissional e mudanças de atitude em relação à Ciência" e "prazer pessoal e aprendizagem em Ciência", a partir do estudo de impacto de Garnett (2003). No intitulado The impact of Science Centers/Museums on the Surrounding Communities, o autor destaca quatro tipos de impactos das atividades do Museu de Ciência: pessoal, social, político e econômico.

O impacto social é o efeito que o Centro ou Museu de Ciências causa nas pessoas, nas 
organizações e na construção, e no ambiente natural. Exemplos: local, regional, turismo internacional, atividades comunitárias, programa de voluntariado, empregos para jovens, parcerias com a comunidade, restauração de equipamentos, estradas, estacionamento, transportes; O impacto político é a influência que um Centro ou Museu de Ciências tem nas políticas do governo e no estabelecimento de prioridades. Ocorre em todos os níveis do governo; O impacto econômico é representado pelos efeitos diretos e indiretos que o Centro ou Museu de Ciência tem na economia local. Inclui indicadores como: "receitas obtidas por vendas aos visitantes", "receitas obtidas pela comunidade a partir dos visitantes", "despesas do Centro de Ciências" e "criação de empregos por consultorias e empregadores externos"; O impacto pessoal designa as mudanças que ocorrem no indivíduo como resultado do seu contato com o Centro ou Museu de Ciências e inclui fatores como prazer pessoal, aumento da habilidade profissional, direcionamento para a formação de carreira [...] mudanças de atitudes em relação à Ciência e aprendizagem em Ciência (GARNETT, 2003, p. 03, tradução e grifos nossos).

Dessa maneira, em função das possíveis mudanças nos professores como resultados do contado com o Museu de Ciência por meio do CFCP, adotamos, no presente trabalho, o impacto pessoal, gerando assim as categorias temáticas em questão.

\section{RESULTADOS E DISCUSSÃO}

Identificamos, com a análise dos resultados, sete unidades de registro, sendo estas reunidas em duas categorias temáticas. Portanto, as unidades de registro "Português e Matemática", "Atividades práticas", "Planejamento", "Interdisciplinaridade" e "Multiplicador" foram agrupadas na categoria temática "Aumento da habilidade profissional e mudanças de atitude em relação à Ciência"; já as unidades de registro "Motivação para aprender Ciência" e "Cursos regulares" foram inseridas na categoria temática "Prazer pessoal e aprendizagem em Ciência".

\section{Aumento da habilidade profissional e mudanças de atitude em relação à Ciência}

Gráfico 1- Distribuição da frequência das unidades de registro $(N=15)$

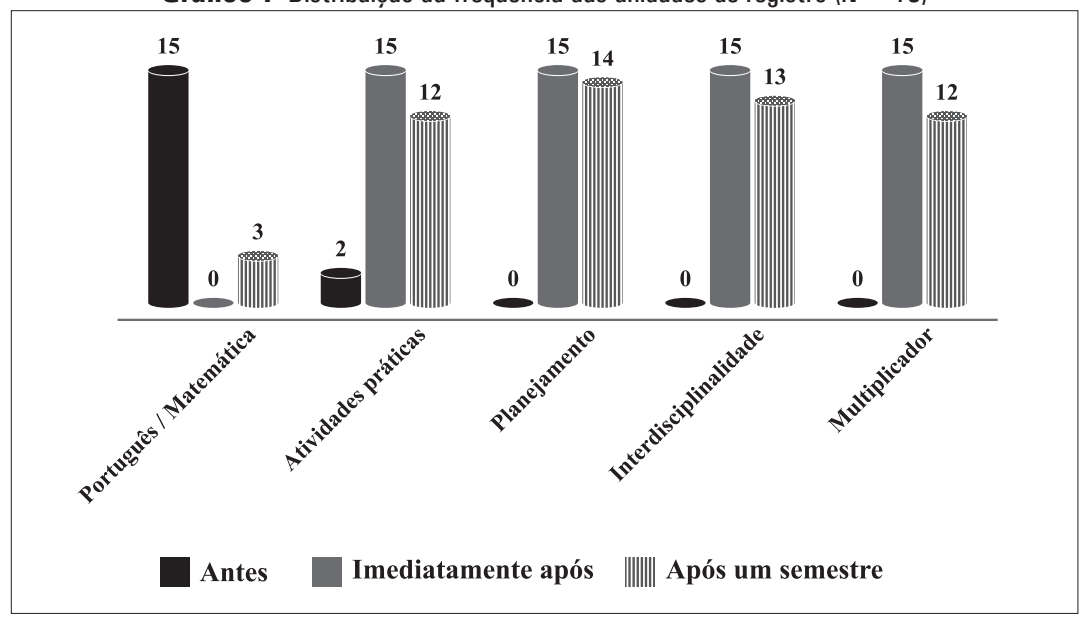


As unidades de registro inseridas na categoria temática "Aumento da habilidade profissional e mudanças de atitude em relação à Ciência" foram divididas em três momentos distintos: antes do curso, imediatamente após o termino do curso e após um semestre (gráfico 1). Podemos verificar, no gráfico 1, que antes de os professores participarem do curso de formação continuada, eles trabalhavam majoritariamente as disciplinas de Português e Matemática (15 respostas). Os relatos a seguir pontuam essa problemática inicial:

Antes, é aquilo que eu até falei no curso durante os primeiros encontros, é, nós somos focados pra ensinar Português e Matemática, então as Ciências, História, Geografia é muito passado por cima. Então as Ciências, principalmente, ficam jogadas a terceiro plano [...] A criança tem que saber e sair lendo! Então as outras matérias são quase nulas dentro da rede pública aonde eu trabalho". (Professor E, Turma I)

Antes eu usava o livro didático, não fazia muitas experiências com as crianças, na verdade pincelava as Ciências e dava mais ênfase à Matemática e Português, Ciências eu deletava.

Deletava mesmo! Dava assim, o básico do básico” (Professor I, Turma I, grifos nossos)

A ênfase dada ao ensino da língua materna e Matemática. em detrimento das demais disciplinas. foi um fator de convergência entre as declarações dos docentes das duas primeiras turmas do curso. Observamos. ao longo das narrativas, a presença de docentes que substituíam a carga horária semanal de Ciências pela disciplina de Língua Portuguesa, em função da necessidade de alfabetização dos alunos. Delizoicov e Angotti (1990) corroboram ao afirmar que, nos anos iniciais do Ensino Fundamental, não é costume abordar os conteúdos de Ciências Naturais. "A prioridade dada à alfabetização e à aritmética leva os professores a deixar em segundo plano os conteúdos de Ciências Naturais [...]" (DELIZOICOV; ANGOTTI, 1990, p. 15).

Assim, partindo da premissa de que o ensino de Ciências ocupa um lugar residual na formação do aluno dos anos iniciais do Ensino Fundamental, constatamos, a partir das falas dos docentes, que muitos gestores coibiam o ensino de Ciências para os anos iniciais. Tal evento ocorria, principalmente em função das políticas nacionais de avaliação dos estudantes do Ensino Fundamental a partir da Avaliação Nacional do Rendimento Escolar (ou "Prova Brasil") e do Sistema Nacional de Avaliação da Educação Básica (Saeb), uma vez que os exames verificam o desempenho dos alunos em Língua Portuguesa e Matemática (PEREIRA, et al. 2013).

Não cabe aqui a discussão acerca dos aspectos intrínsecos às avaliações nacionais, contudo identificamos que os professores participantes do estudo sentiam dificuldades para articular as diferentes áreas do saber, priorizando as disciplinas de Língua Portuguesa e Matemática ao longo do ano letivo. Dessa forma, antes de participar do curso, não percebiam as potencialidades da disciplina de Ciências no processo de alfabetização dos alunos e para a aprendizagem da Matemática. Assim, foi trabalhada, ao longo do curso, a importância do diálogo entre as Ciências e demais disciplinas de forma interdisciplinar, objetivando à formação integral da criança. 
Além da centralidade no ensino das disciplinas de Português e Matemática, notamos o predomínio de aulas de Ciências teóricas e expositivas, conforme o depoimento a seguir: "Bom, antes do curso era mais uma coisa assim teórica né. De livros, de matéria passada no quadro, era uma coisa muito sistemática" (Professor S, Turma I). Desse modo, podemos notar no gráfico 1 que, dos 15 entrevistados, dois eventualmente realizavam atividades práticas por meio de demonstrações, das quais os alunos apenas observavam os fenômenos: "A gente ficava sempre na mesmice e, numa pequena aula, com alguns experimentos demonstrativos, assim, com um vídeo [...]” (Professor L, turma I).

$\mathrm{O}$ depoimento a seguir evidencia que tais metodologias, ancoradas em aulas essencialmente expositivas, provocavam o desinteresse nos alunos pela disciplina de Ciências:

Os alunos falavam que é muito chato: "por que tem que gravar nome?", "por que tem não sei o quê", "não consigo fazer, não consigo decorar isso tia!". Eu entendo que eles não conseguem visualizar aquilo e eu acho que a ciência tem muito da visualização, né! Eles precisam estar num lugar e ver aquilo acontecer, né! (Professora R, Turma I)

Ao longo da entrevista, observamos que, antes do curso, alguns docentes acreditavam que a realização de aulas dinâmicas, com a participação dos alunos nas aulas de Ciências, provocava a desordem em sala, acentuada pelo grande número de alunos. Assim, esses docentes, ao lecionar a disciplina Ciências, utilizavam o livro didático, com aulas essencialmente expositivas. Paixão e Cachapuz (1999) corroboram com esses dados ao afirmarem que a metodologia para o ensino de Ciências no segmento em questão "corresponde a um modelo tradicional da educação na qual se dá muita importância ao respeito e ao silêncio de forma autoritária, onde se prioriza o discurso expositivo do professor para os alunos" (PAIXÃO; CACHAPUZ, 1999, p. 75). De forma contrária, o professor cuja prática pedagógica está ancorada no modelo crítico-reflexivo deve ensinar, buscando a participação e compreensão dos seus alunos. Para Zeichner (2008), o docente deve rejeitar "um modelo transmissivo de ensino que meramente promove a memorização" (p. 546). O professor crítico precisa dar a voz ao seu aluno, deve abrir espaços para debates e discussões em sala de aula com vistas à promoção da autonomia e da formação de sujeitos críticos (ZEICHNER, 2008). Portanto, a realização de atividades práticas, apesar de estimular um ambiente de agitação, tende a criar possibilidades de a criança questionar, propor hipóteses e formular conclusões, estimulando o protagonismo e o espírito crítico do estudante. $\mathrm{O}$ depoimento do professor AL, da turma I demonstra tal mudança de concepção após sua participação no CFCP:

[...] Primeiro, no início era muita bagunça. Porque eles estavam muito acostumados a copiar e a gente costuma dizer que o quadro é a disciplina, porque enquanto o quadro está cheio eles ficam quietos. Então quando a gente leva um pouco pra prática, há uma certa agitação. Teve uma agitação, até uma bagunça, mas também aumentou o interesse, a participação. Porque na verdade, a agitação é uma participação [...]. (Professor AL, Turma I, grifos nossos) 
Ainda nessa corrente, importa destacar o exemplo da professora ML, da turma I. Em seu relato, ela sublinhou que a sua metodologia de ensino antes do curso se restringia à "oralidade e socialização das crianças", por ser tratarem de alunos com deficiência (visão, audição, cognitiva, motora). Na figura 1 e no depoimento a seguir, verificamos a realização de atividades práticas dessa professora com os alunos a partir do uso da "cozinha experimental" presente na escola:

E aí o que aconteceu, com esse curso, minha nossa senhora! Me deu muita visão! Eu vi que eu podia fazer e eu vi que eles gostam! Quando eu ia pra cozinha experimental, essa semana mesmo, agora com a turma, nós vimos essa questão da água. Aí eu aproveitei também e vimos os estados da água, eles viram a fervura, a ebulição, e eu vou falando com eles e eles tocam. Muitos deles são deficientes visuais, é o sentido né, então eu botava o gelo na mão, o vapor, assim pra eles sentirem e eles ficam quietinhos. Eles ficam sentados na mesa e participam com a gente. Então, eu acho assim que o curso, eu já gostava, mas o curso me deu mais condições. (Professora ML, Turma I, grifos nossos)

Figura 1- Atividades com crianças deficientes sobre os estados físicos da água (Professora ML)

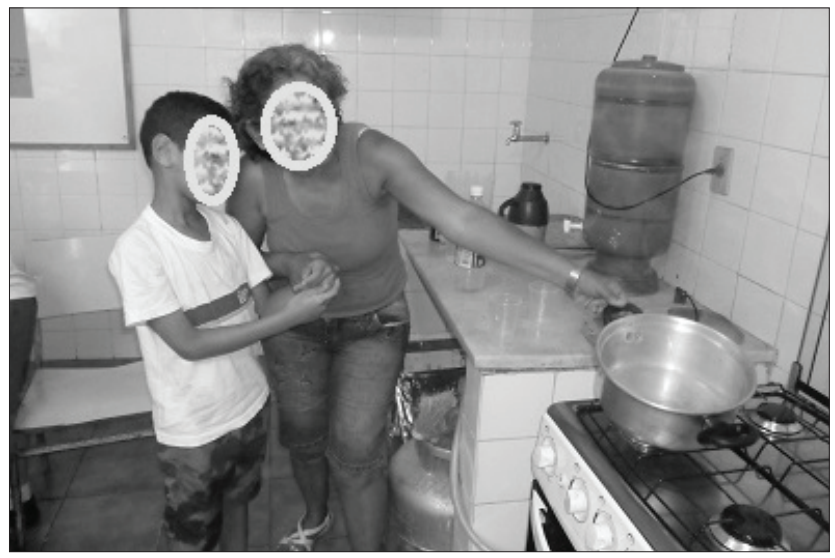

Figura 2- Laboratório de Ciências montado pelo professor, seis meses após o término do curso (Professor S)

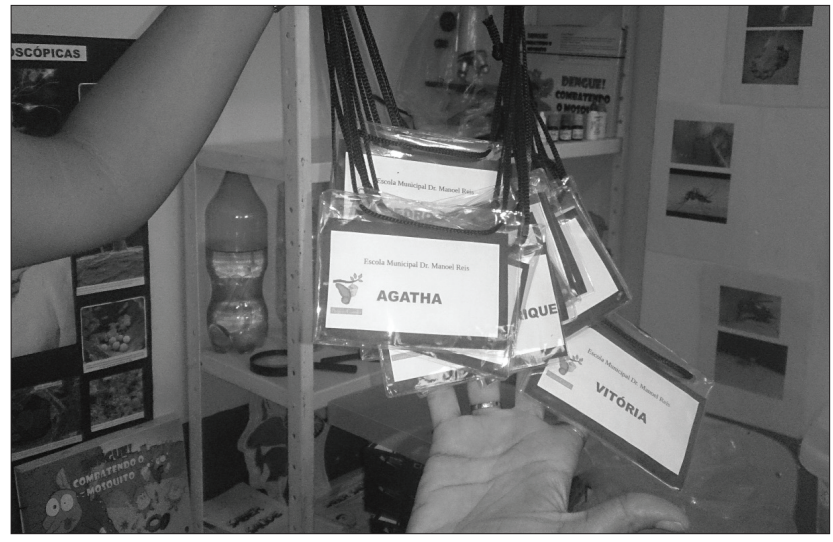


Na figura 2, observamos, ainda, a fotografia de um laboratório de Ciências. O professor S, da turma I detalha em seu relato que, após o término do curso, em função da carência de um espaço de Ciências em sua escola, montou, em uma pequena sala, um laboratório de Ciências para os alunos dos anos iniciais do Ensino Fundamental. Na fotografia (figura 2), ele destaca os crachás com os nomes dos alunos que frequentavam o laboratório de Ciências. Dessa maneira, a organização do espaço propiciou a realização de atividades práticas e experimentais de forma recorrente pelo professor, até mesmo fora do horário das aulas de Ciências. Em sua fala, ele traz o seguinte depoimento: "Muitos alunos ficam comigo após a aula para fazerem vários experimentos de Ciências, tenho alunos de todas as turmas dos anos iniciais" (Professor S, Turma I).

Dessa forma, conforme demonstra o gráfico 1, houve a inserção de atividades práticas nas aulas de Ciências, imediatamente após o término do curso (15 citações), bem como, passados seis meses, 12 docentes permaneceram com tal prática pedagógica, o que evidenciou a sua compreensão acerca da importância de o aluno interagir com o fenômeno, poder criar e fazer relações com o cotidiano.

É, durante o curso eu vi a necessidade de fazer com que meus alunos vissem a ciência. Com experimentos, levá-los pra fora do ambiente escolar, da sala de aula, dos livros, do caderno, sair daquela coisa formal, transportá-los pra que eles vejam como é gostoso aprender Ciências. Ver Ciências e aprender experimentos, é ver, poder ver isso em prática. Aí eu comecei a tirar eles de dentro de sala, por exemplo, eu tentei fazer com eles um jardinzinho, plantando algumas sementes, observando o crescimento dessas sementes e daí fazendo relações com o sol, a chuva, os elementos naturais, fazendo com que eles tivessem mais contato com isso. (Professor E, turma I).

Ressaltamos ainda que a percepção equivocada quanto à natureza da disciplina de Ciências foi modificada, uma vez que a atividade prática em Ciências não se limita à realização de experimentos, e uma atividade experimental precisa ser contextualizada. $\mathrm{O}$ depoimento a seguir grifa tais questões:

[...] Bem no início do curso. Eu tinha dificuldade de relacionar o conteúdo com experiência. Eu achava que só tinha que dar experiência. E assim, [...] as experiências ficaram muito soltas [...] Depois eu fui vendo que o conteúdo de Ciências tinha que ser de uma forma mais prática, mais no cotidiano. Fui vendo que tem assunto que não dá pra explorar na experiência, mas dá pra criança comparar ou trazer experiência de casa. Isso tem acontecido muito! Porque de tudo as crianças sabem um pouco. Hoje não, já tenho uma noção [...] Procurei usar mais jogos, igual aquele joguinho que nós ganhamos aqui do planetário, dos planetas, do sistema solar. Já começamos os jogos, já estou pensando numa aula passeio [...]. (Professor AL, Turma I)

A mudança de atitude em relação à Ciência, acarretando em transformação no contexto escolar, também foi balizada pela valorização do planejamento da disciplina. Portanto, identificamos inicialmente a falta de planejamento da disciplina de Ciências como uma problemática, na qual todos os 15 entrevistados não disponibilizavam tempo para o "planejamento" da disciplina (gráfico 1) - tal 
questão ocorria em função da preocupação apenas com a alfabetização dos alunos. Todavia, durante e imediatamente após o término do programa formativo (gráfico 1), os professores encontravam-se preocupados em preparar previamente suas aulas, sobretudo buscaram empregar metodologias voltadas para um ensino dinâmico.

$\mathrm{Na}$ sequência, notamos que 14 docentes sublinharam as mudanças no planejamento da disciplina (gráfico 1) como um aspecto positivo em sua prática, sobretudo a partir da busca por novas fontes de conhecimentos. O depoimento a seguir do professor I, da turma I, demonstra a valorização atribuída à organização e planejamento da disciplina:

Eu realmente não planejava. Planejava aquela coisa assim, de professora que tem muitos anos [...] eu começava o ano muito bem, planejava e depois largava de mão [...]. Então, quando você começa, e assim que eu vim pro curso e eu comecei a ver alguma coisa, eu vi que precisa ser planejado. Não dá pra chegar na "cara e na coragem" na turma: "ah, eu sei essa matéria! ", ir lá e dar nada sem planejar. Então, a partir daí a gente tem que realmente planejar e fazer bastante pesquisa. Então quando você vem pro curso, você vê que não é só isso. E pra você mudar as práticas, você tem que realmente planejar, organizar [...] (Professor I, Turma I, grifos nossos).

Verificamos também depoimentos que convergiram para a "Interdisciplinaridade". Antes do curso não havia tal preocupação; imediatamente após o curso, todos buscaram a integração das disciplinas e, após um semestre, 13 docentes (gráfico 1) ainda demonstraram exemplos de atividades visando à articulação entre as diferentes disciplinas, conforme o depoimento a seguir:

[...] eu não tinha essa facilidade que eu tenho hoje. [...] são barreiras que a gente coloca de que não vai conseguir [...] “Ah não, vou ficar assim mesmo!” Mas não, a gente fazia muito pouco mesmo, eu acho! A interdisciplinaridade era muito pouca, muito pouca. Agora não! A gente faz toda semana! [...] nós estávamos trabalhando os animais. Minha filha fez até comigo [...] uns quebra-cabeças de mamíferos, de peixes, pra eles montarem o quebracabeça facilzinho pra eles. Aí ali, nós trabalhamos as espécies dos animais com eles. $\mathbf{E}$ ali, a gente começa também e vai pra Matemática, pro Português, pra escrita. A questão ainda de fonema né, eles estão trabalhando as sílabas de apoio. E aí eu pegava os animais com a letra A, com a letra E, e aí fazia a ligação com Português, com Matemática. Eu tenho feito. (Professora ML, Turma I, grifos nossos)

Diante do exposto, percebemos que todos os 15 professores entrevistados compreenderam que a disciplina de Ciências é tão fundamental quanto as demais disciplinas. Podemos ainda inferir, após a análise desses dados, que a introdução de atividades práticas de forma contextualizada com a realidade do aluno representou um exemplo profícuo de transformações no contexto escolar. Identificamos a presença de professores autônomos e preocupados com as questões sociais, tal como preconiza a pedagogia do professor crítico-reflexivo. Nesse sentido, Pimenta (2008) destaca que os professores crítico-reflexivos precisam ser:

[...] capazes de pensar, de articular os saberes científicos, pedagógicos e da experiência 
na construção e na proposição das transformações necessárias às práticas escolares e às formas de organização dos espaços de ensinar e de aprender, compromissados com um ensino com resultados de qualidade social para todas as crianças e os jovens. (Ibid, p. 44).

Assim, constatamos ações de inclusão social, a partir de estratégias de ensino voltadas para crianças com diferentes deficiências, montagem de espaços de ciências preparados para receber os alunos dos anos iniciais de toda a escola, a preocupação em articular as diferentes disciplinas, assim como verificamos o papel de "multiplicadores" dentro da escola. A partir do gráfico 1, podemos observar que 12 participantes apresentaram, em suas falas, elementos que evidenciaram tal aspecto após um semestre. Identificamos nos relatos que suas ações junto aos seus alunos na escola despertavam a curiosidade em outras crianças e essas, por sua vez, pediam para participar de suas atividades. Importa ressaltar, a partir do depoimento do professor E, da turma II, que, em algumas situações iniciais, o processo de mudança pedagógica provocou incômodos entre os gestores, no entanto, diante do interesse dos alunos, a gestão escolar reconheceu a relevância do trabalho do professor:

Aquele bonequinho da sexualidade [...] A escola toda veio pra porta da minha sala, praticamente. E na escola tinha muitas dificuldades no passado com relação a isso, foi uma coisa que eu meio que "peitei" a coordenação pra poder fazer. "Peitei” não, na verdade eu não avisei. E fez o maior sucesso, depois a coordenadora veio até me conhecer e conversar comigo, o que foi bom. E os outros alunos pediram pra assistir essa aula também. O pessoal passou e viu o boneco lá, viram o menino com pênis e a menina com vagina, e veio todo mundo interessado nisso, o interesse inicial era esse. E fui explicando, foi uma aula assim, muito bacana. Isso tá marcado na minha vida! (Professor E, Turma II)

Constatamos, ao longo da entrevista com o professor E, da turma II, que oito meses após o término do CFCP, ao assumir a função de gestor em sua escola, viabilizou a liberação de dois docentes para participar da terceira edição do CFCP, iniciou a organização de uma feira de Ciências na escola, bem como promoveu mudanças nas reuniões pedagógicas em favor de um ensino de Ciências mais dinâmico e inclusivo. O depoimento adiante do professor, exemplifica tais aspectos:

[...] Com os professores, a gente procura sempre estar fazendo atividades, [...] dizendo: "olha só, isso aqui pode ser de alguma forma", eu tenho bastante material do curso (CFCP) que hoje eu passo pra eles também. Tem os centros de estudos que a gente procura sempre trabalhar essa questão da interdisciplinaridade, a gente trabalha bastante isso. E trazendo material o tempo inteiro, a gente procura articular a escola, porque a escola tem essa dinâmica, não seria uma prática de um ou dois ou três professores. Claro que a gente encontra uma barreira, um obstáculo no início, mas a gente vê que conforme os professores vão observando os outros professores que já trabalham com isso, eles começam aos poucos fazer também. (Professor E, Turma II, grifo nosso)

Podemos destacar que os professores foram os principais divulgadores do CFCP, sobretudo por apresentarem para seus colegas os aspectos positivos do curso 
mediante as transformações em sua prática pedagógica. Observamos assim que passado mais de um semestre, foram estabelecidas parcerias entre os professores dos anos iniciais de forma sistemática e organizada a fim de modificarem o ensino de Ciências em sua unidade escolar, conforme pontua o relato adiante:

\begin{abstract}
Esse ano, [...] nós começamos agora, eu tô começando aos poucos com a ideia de trabalhar não só com a minha turma na escola, mas inserir isso nos dois primeiros anos, com a minha turma e a turma de uma colega. A gente está tentando fazer um projeto agora, é, o projeto pro primeiro bimestre, em que as crianças, elas tenham mais contato com isso, que elas possam fazer esses experimentos. A gente vai tentar fazer isso, implantar isso na escola. E aí ver se nos outros anos a gente consegue passar no segundo, terceiro e quarto ano... (Professor E, Turma I, grifos nossos)
\end{abstract}

A função de multiplicadores ressaltou o compromisso dos docentes com a transformação coletiva do ambiente escolar, de tal modo que os gestores e colegas de trabalho reconheceram a importância da disciplina de Ciências para as crianças. Alarcão (1996) ressalta que o professor reflexivo sob a perspectiva crítica deve ir além do seu papel de docente, precisa sair da sua sala de aula, uma vez que a mudança se faz de forma coletiva.

Contudo, convém destacar os depoimentos de três docentes, cujos relatos evidenciam um retorno às antigas práticas. Durante as atividades do CFCP, esses professores se mostraram participativos e dispostos a modificar sua realidade escolar. Entretanto, após mais de um semestre de término do curso, tais docentes apresentaram as precariedades de suas escolas como o fator preponderante para a manutenção da pedagogia tradicional. Pimenta (2008) expõe ainda que, de forma oposta ao cenário brasileiro, países como Espanha, Portugal, Estados Unidos, Inglaterra e França não apenas investiram e transformaram os modelos de formação de professores, mas também "modificaram significativamente suas condições de exercício profissional com jornada e salários compatíveis com um exercício crítico e reflexivo e de pesquisa" (ibid, p. 45). Com isso, considerando a realizado da educação no Brasil, tornam-se necessárias políticas públicas que auxiliem o professor no processo de mudança no contexto escolar.

Vale destacar que a ausência de um acompanhamento recorrente em sala de aula pela equipe técnica do CFCP também pode ter contribuído para tal situação. Esse tipo de retrocesso já foi observado por Jacobucci (2006); em seu estudo, a autora sublinha a relevância da assessoria após a finalização das atividades dos programas formativos:

[...] essa assessoria influi na motivação do professor para realizar um trabalho modificador em sala de aula, visto que após o período do processo de formação no núcleo de divulgação científica, o professor não se vê sozinho na escola e sim apoiado pelas pessoas que compartilharam com ele problemas, ideias e soluções (p. 274).

Diante da ausência de políticas públicas que viabilizem o trabalho do professor, identificamos o fim das atividades do CFCP como uma fragilidade que merece destaque, uma vez que não houve um assessoramento em sala de aula após o término do curso. 


\section{Prazer pessoal e aprendizagem em Ciência}

A análise dos resultados da pesquisa junto aos 15 professores, após um semestre de término do curso, também possibilitou a organização de duas unidades de registro que foram reunidas na categoria temática "Prazer pessoal e aprendizagem em Ciência” (quadro 1).

Quadro 1 - Menções por unidade de registro

\begin{tabular}{|c|c|c|}
\hline & Unidades de registro & No absoluto/menções \\
\hline 1 & Motivação para aprender Ciências & 14 \\
\hline 2 & Qualificação profissional em Ciências & 06 \\
\hline
\end{tabular}

No quadro 1, a unidade de registro "Motivação para aprender Ciências" aparece com 14 menções. De maneira geral, os docentes chegaram ao curso interessados pelo tema, no entanto muitos não compreendiam a importância da disciplina para a formação do sujeito.

Olha, antes do curso eu não via o ensino de Ciências como eu vejo hoje. Antes do curso eu via como um complemento simplesmente. [...] não tinha a mesma importância [...] a partir do curso, eu comecei a pesquisar outras coisas. Então fui em busca de outras informações. (Professor E, turma I)

Após o curso, observamos o grande interesse dos docentes por assuntos ligados às Ciências e temas correlatos. Partindo da premissa de que não existe conhecimento pronto e acabado, os professores não se acomodaram aos conteúdos tratados no curso, pois incorporaram o hábito de buscar novos conhecimentos mediante leituras e pesquisas em fontes para além do livro didático. A busca por novos conhecimentos passou a ser um motivo de satisfação e prazer pessoal, conforme exemplifica o depoimento a seguir:

Eu virei assim meio que um fanático por astronomia [...] É, marcou! Eu sempre gostei, mas aí depois disso eu busquei estudar, enfim, de uma outra forma, de forma mais organizada. Era uma coisa que eu gostava desde a minha adolescência, só que é aquilo, você não sabe como organizar as áreas do conhecimento. Hoje eu já organizo, já li vários, e vários, e vários artigos, enfim, estou sempre em sites visitando [...] Não tinha esse hábito! [...] (Professor E, Turma II)

Com vistas à qualificação profissional, a partir de cursos regulares, estabelecemos a unidade de registro "Qualificação profissional em Ciências" (quadro 1). Com isso, identificamos que seis dos 15 entrevistados foram buscar cursos de graduação e pós-graduação em Ciências. Identificamos cursos de Licenciatura em Biologia, Especialização em Neurociências, e também o interesse de uma professora por um curso de Pós-Graduação Strictu Sensu, uma vez que, no momento da entrevista, esse estava se preparando para o Mestrado em Astronomia. 
O relato a seguir exemplifica esses resultados:

[...] Fui fazer neurociências [...] fiquei muito interessada, por essa questão até do entendimento de como se dá a aprendizagem, como que o cérebro trabalha tudo isso. Então, foi assim, se eu não tivesse ido lá fazer o curso, não teria assistido a palestra e não teria começado o curso [...] (Professor L, Turma I)

A busca desses professores por novos conhecimentos, visando ao seu aperfeiçoamento profissional e pessoal, evidenciou o impacto pessoal nos docentes, sob o viés crítico-reflexivo, uma vez que o professor reflexivo deve buscar o seu próprio desenvolvimento, sendo consciente do seu papel na sociedade (ALARCÃO, 1996). Dessa maneira, podemos inferir que ir ao encontro de novos conhecimentos e saberes, buscar espaços de qualificação, repensar o seu papel como docente e, principalmente, como sujeito, é fundamental para o processo de reflexão crítica do professor.

\section{CONSIDERACְÕES FINAIS}

A presente investigação possibilitou tecer reflexões sobre a temática da formação continuada de professores dos anos iniciais da educação básica, descortinou um cenário de desmotivação e frustração no tocante às aulas de Ciências, tendo em vista que seus depoimentos foram balizados por conflitos e obstáculos que os impediam de trabalhar tal disciplina de maneira profícua junto aos alunos.

Diante desse cenário, alicerçada ao referencial do professor crítico-reflexivo, foi estabelecida uma dinâmica ao longo do curso que fomentou um ambiente de discussão, propiciou a troca de vivências pedagógicas e experiências, além de reflexões a respeito das questões sociais e políticas que perpassam a educação. Com isso, o ato de ouvir a si mesmo e aos outros foi um elemento de reflexão sobre suas próprias concepções a respeito da educação científica e o contexto escolar. Nessa corrente, Cardoso et al. (2005, p. 82-83) afirmam que "a reflexão sobre o seu ensino é o primeiro passo para quebrar o ato de rotina, possibilitar a análise de opções múltiplas para cada situação e reforçar a sua autonomia face ao pensamento dominante de uma dada realidade".

Após a análise dos dados da pesquisa, podemos concluir que um programa de formação de professores de um Museu de Ciência, baseado no modelo crítico-reflexivo, promoveu o impacto pessoal (GARNETT, 2003) nos docentes participantes, resultando em prazer pessoal, aumento da habilidade profissional, mudanças de atitudes em relação à Ciência e aprendizagem em Ciência. Encontramos, após um semestre, professores ainda motivados, introduzindo novas metodologias para o ensino da disciplina de Ciências, dentre as quais a presença de atividades experimentais, com o uso de recursos didáticos adaptados à realidade dos alunos, utilização de espaços alternativos da escola para demonstrações e discussões acerca dos fenômenos da natureza, visitas a espaços de educação não formal, entre demais alternativas apresentadas pelos próprios sujeitos da pesquisa no intuito de inserir as crianças em um contexto de descobertas. O programa formativo também aguçou nos docentes o interesse por assuntos ligados às 
Ciências e temas correlatos, bem como incorporaram o hábito de buscar novos conhecimentos, além de alguns irem buscar novas qualificações na área. Cabe ressaltar que, ao longo dos depoimentos, identificamos, na fala dos 15 professores, a presença de muitas limitações impostas pelas políticas internas e externas ao processo educativo, haja vista o contexto educacional brasileiro. Todavia, muitos buscaram transpô-las, visando a uma educação de qualidade para os alunos.

Diante do exposto, identificamos professores críticos, reflexivos e autônomos, engajados em ações voltadas para a transformação do contexto escolar e inclusão social, e ainda comprometidos com a educação plena da criança.

Importa destacar alguns fatores que foram essenciais para a promoção de mudanças nos docentes, tais como a carga horária mínima de 100h, viabilizando debates sobre a realidade escolar e questões sociais; a equipe técnica multidisciplinar com formação em Ciências e em Educação; o diálogo constante e troca de experiências entre os docentes participantes e a equipe técnica; bem como a estruturação do curso de acordo com as necessidades do público-alvo. A visita aos Centros e Museus de Ciência também foi marcante para os professores, onde muitos retornaram com seus alunos, com seus filhos ou sozinhos; cada participante compreendeu as possibilidades de apropriação dos Centros e Museus de Ciência, como uma ferramenta para a aquisição de novos conhecimentos, levando em conta os alunos e a sua própria formação intelectual.

Por fim, é evidente a importância de ações formativas para professores dos anos iniciais da educação básica para a melhoria do ensino de Ciências. Sobretudo, quando estes são oferecidos por Centros e Museus de Ciência em parceria com as universidades, com propostas metodológicas que propiciem um ambiente crítico reflexivo. Assim, acreditamos que, a longo prazo, as universidades e centros de pesquisa em parceria com os Centros e Museus de Ciência poderão contribuir para a transformação da realidade escolar do ensino básico brasileiro.

\section{REFERÊNCIAS}

ALARCÃO, I. Ser professor reflexivo. In: ALARCÃO, I. S. (Coord.). Formação reflexiva de professores: estratégias de supervisão. Porto: Porto Editora, 1996. p. 171-189.

AUGUSTO, T. G. S. A formação de professoras para o ensino de ciências nas séries iniciais: análise dos efeitos de uma proposta inovadora. 2010, 315p. (Doutorado em Educação). Faculdade de Educação, Universidade Estadual de Campinas, Campinas, 2010.

BARDIN, L. Análise de conteńdo. 4. ed. Lisboa: Edições 70, 2013. 281p.

BRASIL. Parâmetros curriculares nacionais: ciências naturais/Secretaria de Educação Fundamental. Brasília: MEC/SEF, 1997. 136p.

CARDOSO, A. M. et al. O movimento da autonomia do aluno: repercussões a nível da supervisão. In: ALARCÃO, I. S. (Coord.). Formação reflexiva de professores: estratégias de supervisão. Porto: Porto Editora, 1996, p. 63-88.

CARVALHO, A. M. P; GIL-PÉREZ, D. Formação de professores de Ciências: tendências e inovações. $10^{a}$ ed. São Paulo: Cortez, 2011. 127 p.

CONTRERAS, J. A autonomia de professores. 2. ed. São Paulo: Cortez, 2012

DELIZOICOV, D.; ANGOTTTI, J. A. Metodologia do ensino de Ciências. São Paulo: Cortez, 1990. 207 p. GARNETT R. The Impact of Science Centers/Museums on their Surrounding Communities. Canberra, 
Formação continuada de professores dos anos iniciais da

Educação Básica: impacto do Programa Formativo de um Museu

de Ciência a partir do viés crítico-reflexivo

Austrália: Questacon, 2003. Disponível em: http://www7.nationalacademies.org/bose/Impact_ Study_Final_Report_InformalSci_Resource.pdf. Acesso em: 16 jun. 2014.

JACOBUCCI, D. F. C. A formação continuada de professores em Centros e Museus de Ciências no Brasil. 2006, 302p. Tese (Doutorado em Educação). Faculdade de Educação, Universidade Estadual de Campinas, Campinas, 2006.

JACOBUCCI, D. F. C.; MEGID NETO, J. Passado e presente da formação continuada de professores nos Centros e museus de ciências brasileiros. In: VIII Encontro Nacional de Pesquisa em Educaşão em Ciências; I Congreso Internacional de Investigación en Enseñanza de las Ciencias. UNICAMP, Anais... 2011.

LIBÂNEO, J. C. Reflexividade e formação de professores: outra oscilação do pensamento pedagógico brasileiro. In: PIMENTA, S. G; GHEDIN, E. (Org.). Professor reflexivo no Brasil: gênese e crítica de um conceito. 5 ed. São Paulo: Cortez, 2008, p. 53-79.

LONGHINI, M. D. O conhecimento do conteúdo científico e a formação do conteúdo científico e a formação do professor das séries iniciais do Ensino Fundamental. Investigações em Ensino de Ciências. Porto Alegre, v. 13, n. 2, p. 241-253, 2008.

LÜDKE, M. ANDRÉ, M. E. D. Pesquisa em educação: Abordagens Qualitativas. São Paulo: EPU, 1986. 99p. NEIVA-SILVA, L.; KOLLER, S. H. O uso da fotografia na pesquisa em Psicologia. Estudos de Psicologia. v. 7, n. 2, p. 237-250, 2002.

NÓVOA, A. Formação de professores e profissão docente. In: NÓVOA, A. (coord.). Os professores e a sua formação. Lisboa: Dom Quixote, 1995, p.14-33.

PAIXÃO, M. F.; CACHAPUZ, A. La enseñanza de las Ciencias y la formación de profesores de enseñanza primaria para la reforma curricular: de la teoria a la práctica. Enseñanza de las Ciencias. Barcelona, v.17, n.1, p. 69-77, 1999.

PAULA, L; PEREIRA, G; PAULA, L; COUTINHO-SILVA, R. Formação continuada de professores em Centros e museus de ciências: um olhar acerca dos programas oferecidos nestes espaços. Latin American Journal of Science Education, v. 1, n. 2, p. 22037-22037-8, nov. 2014.

PEREIRA, G. R. O ensino de Ciências nos anos iniciais do Ensino Fundamental e a formaşão continuada de professores: implantação e avaliação do programa formativo de um Centro de Ciência. 2014, 231p. Tese (Doutorado em Ciências Biológicas- Biofísica). Instituto de Biofísica Carlos Chagas Filho, Universidade Federal do Rio de Janeiro, Rio de Janeiro, 2014.

PEREIRA, G. R. et al. Ciências, Linguagens e Atividades Interativas na Educação básica. In: IV Seminário do Observatório da Educação. Brasília, Capes, Anais... 2013. p.1-8. Disponível em http:// seminarios.capes.gov.br/observatorio-da-educacao/resumos.html. Acesso em 12 dez. 2013.

PIMENTA, S. G. Professor reflexivo: construindo uma crítica. In: PIMENTA, S. G; GHEDIN, E. (Org.). Professor reflexivo no Brasil: gênese e crítica de um conceito. 5 ed. São Paulo: Cortez, 2008. p. 17-52.

RABONI, P. C. A. Atividades práticas de ciências naturais na formação de professores para as séries iniciais. 2002, 131p Tese (Doutorado em Educação). (Doutorado em Educação). Faculdade de Educação, Universidade Estadual de Campinas, 2002.

RAMOS, L. B. C.; ROSA P. R. S. O ensino de Ciências: fatores intrínsecos e extrínsecos que limitam a realização de atividades experimentais pelo professor dos anos iniciais do Ensino Fundamental. Investigacões em Ensino de Ciências, v. 13, n. 3, p. 299-331, 2008.

SCHÖN, D. Educating a reflexive practitioner: toward a new design for teaching and learning in the professions. São Francisco: Jossey Bass, 1987. 347p.

VIANA, D. M.; CARVALHO, A. M. P. Formação permanente: a necessidade da interação entre a ciência dos cientistas e a ciência da sala de aula. Ciência \& Educaşão, Bauru, v. 6, n. 1, p. 31-42, 2000.

ZEICHNER, K. M. The promise and pitfalls of reflective teacher education. In: III Congreso Nacional de Investigación Educativa. Cidade do México: Universidad Pedagógica Nacional, Anais... 1995.

ZEICHNER, K. M. Uma análise crítica sobre a "reflexão" como conceito estruturante na formação

Revista Ensaio | Belo Horizonte | v.19 | e2470 | 2017 
docente. Educaşão e Sociedade, Campinas, v. 29, n. 103, Mai/Ago. 2008. Disponível em:<http://www. scielo.br/scielo.php?script $=$ sci_arttext\&pid $=$ S0101-73302008000200012\&lng $=$ en\&nrm $=$ iso $>$. Acesso em: 19/08/2014.

\section{NOTAS}

${ }^{1}$ Pesquisa financiada pela Coordenação de Aperfeiçoamento de Pessoal de Nível Superior (CAPES)

${ }^{2}$ Programa fruto da parceria entre a CAPES, o INEP e a Secretaria de Educação Continuada, Alfabetização, Diversidade e Inclusão tem o propósito de intensificar a articulação entre as atividades da pós-graduação stricto sensu, das licenciaturas e das escolas de educação básica.

Submetido em 24/09/2015

Aprovado em 09/05/2017

\section{Contato:}

Grazielle Rodrigues Pereira

Espaço Ciência InterAtiva

Campus Mesquita do Instituto Federal de Educação, Ciência e Tecnologia do Rio de Janeiro

Rua Baronesa de Mesquita, S/N,

Praça João Luiz do Nascimento, Centro

CEP: 26551-540 - Mesquita, RJ - Brasil 